Afghani patient for as long as 35 days, Ricard says. "It's pointless to simply save a life and then the next morning, say whatever happens to this person, happens to this person. You want to take them to a hospital where they don't have an ICU and this person is still intubated? [Yet keeping that person] occupies a bed, a nurse, 2 nurses, 3 nurses. That was the main challenge, space itself, not really what we could, what we couldn't do, with the equipment, the different specialties and all that stuff. The challenge is the bed space. But you cannot be shy when it's time to actually make room. That's the approach I took. I didn't want to have beds that were empty ... and say no to people that we could actually save. So I filled them up and I lived with it. Sometimes, your team has different opinions. You can be burning out your personnel, so it's a difficult choice."

At times, though, fate and circumstance exact their toll, Ricard adds, recalling a case in which an intubated, partially paralyzed 7-year-old child with a piece of grenade shrapnel embedded in his brain had to be transferred to Mirwais, where he subsequently died.

"You know that he doesn't have a future in a country where something like rehab doesn't exist and he stays paralyzed. So, in a certain sense, if you send the person to Mirwais and it doesn't go well, you know at least you did the most that you could do to assess and to save a life and then you have to move on. You cannot keep these people forever. Those are the cases where you have to say okay, well we tried to save them and then whatever happens now is going to have to happen within their own system."

"It's tough. But those decisions have to be made. It's impossible to have a I5-bed hospital that is covering a city the size of Toronto."

Mirwais officials didn't hesitate to pick up the child, or other Afghani patients, even when they know they lack surgical capability and that the prognosis is dismal, Ricard adds. "That was the reaction of some of their doctors, to say: 'Don't try to protect us against ourselves. We want to be involved in taking care of our own patients." - Wayne Kondro, $C M A J$

DOI:I0.I503/cmaj.070838

\section{Malaise at Mirwais}

Published at www.cmaj.ca on July 4, 2007.

$\mathrm{F}$ or the seriously ill, being treated at Khandahar's Mirwais Hospital is all but a death sentence, says an ex-Vancouver paramedic who now serves as country director for a non-governmental organization operating in Afghanistan.

"The idea of calling it a hospital is outrageous," says Edward McCormick, country director for the Afghanistan office of Senlis Council, the Paris-based international development and security policy think tank.

McCormick, who earlier this year crafted a report entitled War zone hospitals in Afghanistan: a symbol of wilful neglect, says conditions are so bad at Mirwais that it is little more than a means of getting patients "out of the wind."

Canadian military physicians often find themselves in ethical quandaries about transferring Afghani soldiers, policemen and civilians to Mirwais after treating their trauma injuries at a multinational medical unit (see page I3I).

They're justified in their concern, McCormick says. Mirwais isn't just "poorly equipped. It's not equipped." The hospital, built in the early I970s, now serves a population of nearly 3 million people. With 450 beds, that translates into a 0.15 bed per thousand ratio, compared with an Organization for Economic Co-operation and Development average of 4.I.

"There's only one working X-ray. The room called the ICU [intensive care unit] is a big open ward with more beds than there should be, with no precautions taken in terms of isolation," McCormick notes. "There is no suction equipment. There is no monitoring equipment. There are no ventilators and they don't have any resuscitation equipment. They have one BVM [a handheld resuscitation device/ambu bag]; it's locked in a cupboard. There's no laryngoscope. There is no McGill forceps. [The latter 2 devices are used to clear obstructed air passages.] When I asked them about cardiac arrest response, they said 'That just means there's an empty bed."'

"The only little bit of blood they get is from family members of patients. There's no blood bank, per se."

The hospital's lab "looked like a museum from something around Dr. [Norman] Bethune's time. They had really old Erlenmeyer flasks up on a bench. It looked more like a prop from a movie studio."

Nor does Mirwais have central heating, air conditioning or laundry services. "The place is filthy. There's dead flies literally piled up on the window sills and floors," McCormick says. In the pediatric ward, "the smell of urine is really apparent."

"It looks like an intertidal zone with children being incontinent in beds. On one occasion, I saw a child with polio and [staff] were waiting for lab results to come back from Pakistan, while this kid was in an open ward. It's worse than a place to house people. It's a vector for infection."

McCormick's report paints a dismal picture of virtually every facet of hospital operations. There is no record-keeping. Oxygen tanks are corroded and at risk of exploding. There is no pharmacy; if a doctor prescribes a medicine, the patient's family must hunt for it in the city. Doctors are paid an average US $\$ 50$ per month, while nurses earn US\$35. Both require that patients provide a "gift" to receive attention.

McCormick also argues that the state of Mirwais is an indictment of international reconstruction efforts, including the \$139 million the Canadian International Development Agency has spent in the war-torn country. "We haven't seen any sign of that spending anywhere" and particularly, within the hospital system. - Wayne Kondro, CMAJ

DOI:Io.I503/cmaj.070852 